Printed Version: (ISSN 2090-5262)

Online Version: (ISSN 2090-5270)

March 2012, Volume 2, No. 1 Pages (12 - 20)

\title{
Identifying the Standard Levels for Some Specific Physical Skills for Tennis Female Juniors from 9-12 Years.
}

\author{
Yasser K. Ghoniem*
}

\begin{abstract}
:
The aim of this study was to identify the standard level for some physical ability variables, which could assist in the selection process of young female tennis players in Egypt. Strength, power, agility, aerobic endurance, speed and flexibility were measured for 57 high level female junior tennis players (age: 10.48 +/- 1.37yrs; height: 132.49 +/- $10.83 \mathrm{~cm}$; weight 35.67 +/- $10.40 \mathrm{~kg}$ ). Percentile scores were calculated for every variable. The researcher recommends using these scores to evaluate the fitness levels for $9-12$ years old female tennis players in order to establish current level of physical abilities and as a part of talent identification process.
\end{abstract}

Keywords: standard levels - physical abilities - tennis female juniors.

\section{Introduction and research problems:}

\begin{abstract}
A $\mathrm{n}$ advanced tennis player must possess tennis skills to be a successful player in the game of tennis. At the professional level, players at the top of the rankings possess physical, mental and emotional tennis skills which mean that juniors must possess a minimum standard level of these abilities in order to achieve higher levels in this sport. Also in Egypt we have a shortage in standard levels for measuring physical, mental and emotional abilities in sports field generally and in tennis specifically.
\end{abstract}

Abdelkhalek (2005) agreed with Burgess (2009) as they both mentioned that choosing the appropriate ore for sports activities is the first step of success and achieving the required target, so athletes should be chosen on scientific basis as wrong choices are considered to be a waste of time and money. Also physical abilities are the main determents of selection in sports field as they allow athletes to apply technical and tactical skills properly. (9:40) (21)

Kirchner (1988) also confirmed that physical abilities are the main core of knowledge and

\footnotetext{
* Assistant Professor: the department of games training, the Faculty of PhysicalEducation for Boys, Alexandria University, Egypt.
}

information in one hand and applying technical and tactical skills in the other hand where its lack prevents juniors from the proper practice of the chosen sports activity. (13:97)

Gallahue (1988) and Wall et al (1995) agreed that the availability of physical abilities for junior female tennis players is a major requirement as it is directly linked to the level of achievement in sports field as these abilities are linked together in an integrated way to fulfill the skills in a proper theme. (10:22) (24:15)

Wolstencroft (2002) defined talent identification as the process of recognizing current .participants with the potential to become elite performers and predicting their performance over various periods of time by measuring physical, physiological, psychological and sociological attributes. (7)

Kluka (2008) stated that Variables used for talent id should be intuitively relevant to performance. Critical variables include those that are underlying characteristics that are common among all individuals who achieve a high level of athletic success within a sport discipline, but are not necessarily capable of differentiating among elite level performers. (5)

MacCurdy (2011) agreed with Wolstencroft (2002) and recommended six areas for coaches to consider when identifying tennis talents: 
physiological, physical, psychological, technical/tactical, results and intangibles. Physiological attributes include parameters such as height, weight and arm span. (6) (7)

Hamad (1996), Elbosaty (1998), Allawy (1998) and Aboabda (2001) all agreed that physical preparation is very vital to juniors and possible talents as it aims for developing the specific physical elements that are related directly to the specific sports activity to reach the highest levels of competition (16:147) (3:24) (18:80) (11:36)

Elkholy et al (2001) pointed out that tennis has became a source of attraction for juniors who aim to practice sports for gaining fitness, shape and healthy life style which means that any healthy individual is capable of practicing tennis, but when those juniors aims for transforming into the competitive stage this needs further work on developing movement skills, fitness elements, tactical skills as well as psychological and mental skills (2:232)

Gabr (2004) stated that physical fitness is the major factor that resolves the winning edge in tennis games especially when levels are so close $(4: 19)$

Mirhosseini et al (2007) stated that despite difficulties in predicting long-term success in young players, the age-based model for physical abilities may be useful in establishing baseline reference data to select and develop talent in athletes. (23)

Wadiea (2007) confirmed that fitness is the way to reach the peak of tennis performance to be able to play a long game that may last for more then 3 or 4 hours according to the level of competition. (8:278)

Farahat (2001) stated that the importance of standards lies in determining the position of the player in the sample group and determining his or her level and evaluating the performance in comparison to different levels. $(15: 174)$

Lacourse et al (1995) stated that the primary factors that separated the higher versus lower ranked female tennis junior players were greater strength, speed, agility, power, and vertical jump. (14)
Also the starting age of practicing tennis is the age stage between 9 and 12 years old as most studies and researches agreed.

Within the limits of the researcher's information and his experience as an assistant professor and a tennis coach, he did not meet a research that aimed for developing physical tests for female tennis juniors form 9 - 12 years that aims for determining the standard levels for fitness elements for this sample population to be used among all female tennis junior players in Egypt as a standard that must be achieved to reach the highest required national or international levels.

\section{Research aim and thesis:}

The aim of this study was to identify the standard level for some physical ability variables, which could assist in the selection process of young female tennis players between 9 and 12 years old in Egypt.

\section{Research procedures:}

- Research method: The researcher used the descriptive survey method where some measurements were applied on the research sample to assess their fitness elements levels.

- Research Sample: The sample was intentionally chosen among the high level female junior tennis players aged $9-12$ years who are registered in the Egyptian tennis federation from several clubs in Cairo and Alexandria with $\mathrm{n}=57$ (age: $10.48+$ +$1.37 \mathrm{yrs}$; height: $132.49+/-10.83 \mathrm{~cm}$; weight $35.67+/-10.40 \mathrm{~kg}$ ).

- Research place: The research was applied in several tennis courts in clubs inside Alexandria and Cairo.

- Time range: The research was applied during 2010/2011

\section{Pilot studies:}

1st pilot study: That was conducted to determine the main physical abilities in tennis and the most proper tests for measuring those abilities. The results determined the main physical abilities for practicing tennis according to the 
experts' opinions and the survey for previous studies and researches. (Appendix 1).

2nd pilot study: That was conducted to confirm the results of the first pilot study using the views of the experienced personnel in this field of tennis with the following terms and conditions:

Should be a holder of PhD of physical education with tennis or measurement and evaluation major
Should be a certified tennis coach by the national federation with an experience that is not less than 10 years

The results of the 2 nd pilot study concluded the most important physical elements that are required for practicing tennis as well as the most proper tests that can be used for measuring these abilities as follows:

Table (1): The physical abilities and their proper tests for tennis female juniors from 912 years.

\begin{tabular}{|c|l|l|}
\hline S & \multicolumn{1}{|c|}{ The measured physical ability } & \multicolumn{1}{c|}{ The proper test } \\
\hline 1 & Cardiovascular Endurance & 600 m running \\
\hline 2 & Speed - Strength "or" Power & Throwing a 1 kg medical ball with both hands \\
\hline 3 & Muscular Endurance & Sitting from lay down position \\
\hline 4 & Muscular strength & Legs power test \\
\hline 5 & Speed & 20 m running \\
\hline 6 & Flexibility & Stand and reach test \\
\hline 7 & Agility & Cubes race test $4 \mathrm{x} 9 \mathrm{~m}$ \\
\hline
\end{tabular}

Table (2): Statistical significance for the physical abilities for the research sample.

\begin{tabular}{|l|c|c|c|c|c|c|}
\hline $\begin{array}{l}\text { Statistical } \\
\text { significance }\end{array}$ & $\begin{array}{c}\text { Arithmetic } \\
\text { meansical }\end{array}$ & SD & $\begin{array}{c}\text { Min } \\
\text { value }\end{array}$ & $\begin{array}{c}\text { Max } \\
\text { value }\end{array}$ & skewness & Kurtosis \\
\hline Muscular strength & 96.09 & 56.61 & 0.00 & 180.00 & 0.03 & -1.53 \\
\hline Speed & 4.48 & 0.62 & 3.11 & 5.84 & -0.15 & -0.28 \\
\hline Power & 349.08 & 81.75 & 200.00 & 551.00 & 0.46 & -0.24 \\
\hline Aerobic endurance & 232.00 & 27.83 & 175.00 & 275.00 & -0.31 & 0.35 \\
\hline Muscular endurance & 39.50 & 11.01 & 18.00 & 74.00 & 0.65 & 1.08 \\
\hline Agility & 35.54 & 7.68 & 18.00 & 58.00 & 0.49 & 2.10 \\
\hline Flexibility & 12.53 & 0.96 & 10.51 & 14.32 & 0.04 & -0.81 \\
\hline
\end{tabular}


Table (3): The differences between both application in the pilot study for confirming reliability coefficient (N=10)

\begin{tabular}{|c|c|c|c|c|c|c|c|c|c|}
\hline \multirow{2}{*}{$\mathbf{S}$} & \multirow{2}{*}{$\begin{array}{l}\text { Statistical } \\
\text { significance }\end{array}$} & \multicolumn{2}{|c|}{ 1st application } & \multicolumn{2}{|c|}{$2^{\text {nd }}$ application } & \multicolumn{2}{|c|}{$\begin{array}{c}\text { Difference } \\
\text { between means }\end{array}$} & \multirow{2}{*}{$\mathbf{T}$} & \multirow{2}{*}{$\begin{array}{l}\text { Reliability } \\
\text { coefficient }\end{array}$} \\
\hline & & Mean & SD & Mean & SD & Mean & SD & & \\
\hline 1 & Leg muscles strength & 72.20 & 11.14 & 76.80 & 13.83 & $4.60-$ & 3.91 & 2.63 & 0.97 \\
\hline 2 & 20 m running & 3.89 & 0.59 & 4.17 & 0.53 & $0.28-$ & 0.33 & 1.90 & 0.84 \\
\hline 3 & $\begin{array}{c}\text { Throwing medical } \\
\text { ball }\end{array}$ & 3.69 & 0.67 & 4.22 & 0.43 & $0.53-$ & 0.58 & 2.08 & 0.53 \\
\hline 4 & $600 \mathrm{~m}$ running & 12.90 & 0.81 & 13.25 & 0.88 & $0.35-$ & 0.46 & 1.67 & 0.85 \\
\hline 5 & $\begin{array}{l}\text { Sitting from lay down } \\
\text { position } \\
\end{array}$ & 32.00 & 7.35 & 36.80 & 7.09 & $4.80-$ & 5.17 & 2.08 & 0.74 \\
\hline 6 & Stand and reach test & 35.20 & 8.87 & 31.00 & 8.15 & 4.20 & 5.12 & 1.83 & 0.82 \\
\hline 7 & Cubes race $4 \times 9 \mathrm{~m}$ & 10.73 & 0.45 & 10.66 & 0.57 & 0.07 & 0.26 & 0.56 & 0.90 \\
\hline
\end{tabular}

* Significant at $0.05=2.262$

Table (4): The self reliability coefficient for the physical tests $(N=10)$

\begin{tabular}{|c|c|c|}
\hline $\mathbf{S}$ & $\ln ^{2}$ & Self- honesty coefficient \\
\hline 1 & Leg muscles strength & 0.985 \\
\hline 2 & 20 m running & 0.917 \\
\hline 3 & Throwing medical ball & 0.728 \\
\hline 4 & $600 \mathrm{~m}$ running & 0.922 \\
\hline 5 & Sitting from lay down position & 0.860 \\
\hline 6 & Stand and reach test & 0.906 \\
\hline 7 & Cubes race $4 \times 9 \mathrm{~m}$ & 0.949 \\
\hline
\end{tabular}

Tables $3 \& 4$ show that the reliability and selfhonesty coefficients for these tests for tennis juniors were between $0.53,0.97$ and 0.827 , 0.985 respectively which reflects the high scientific coefficients for these tests that means that the tests are highly recommended to evaluate this research variables.

After the tests were carried out, the statistical processing was applied on the raw data using:

- Arithmetic mean

- Median

- Standard deviation
- Skewness

- Kurtosis

- Relation coefficient

- $\mathrm{T}$ test 


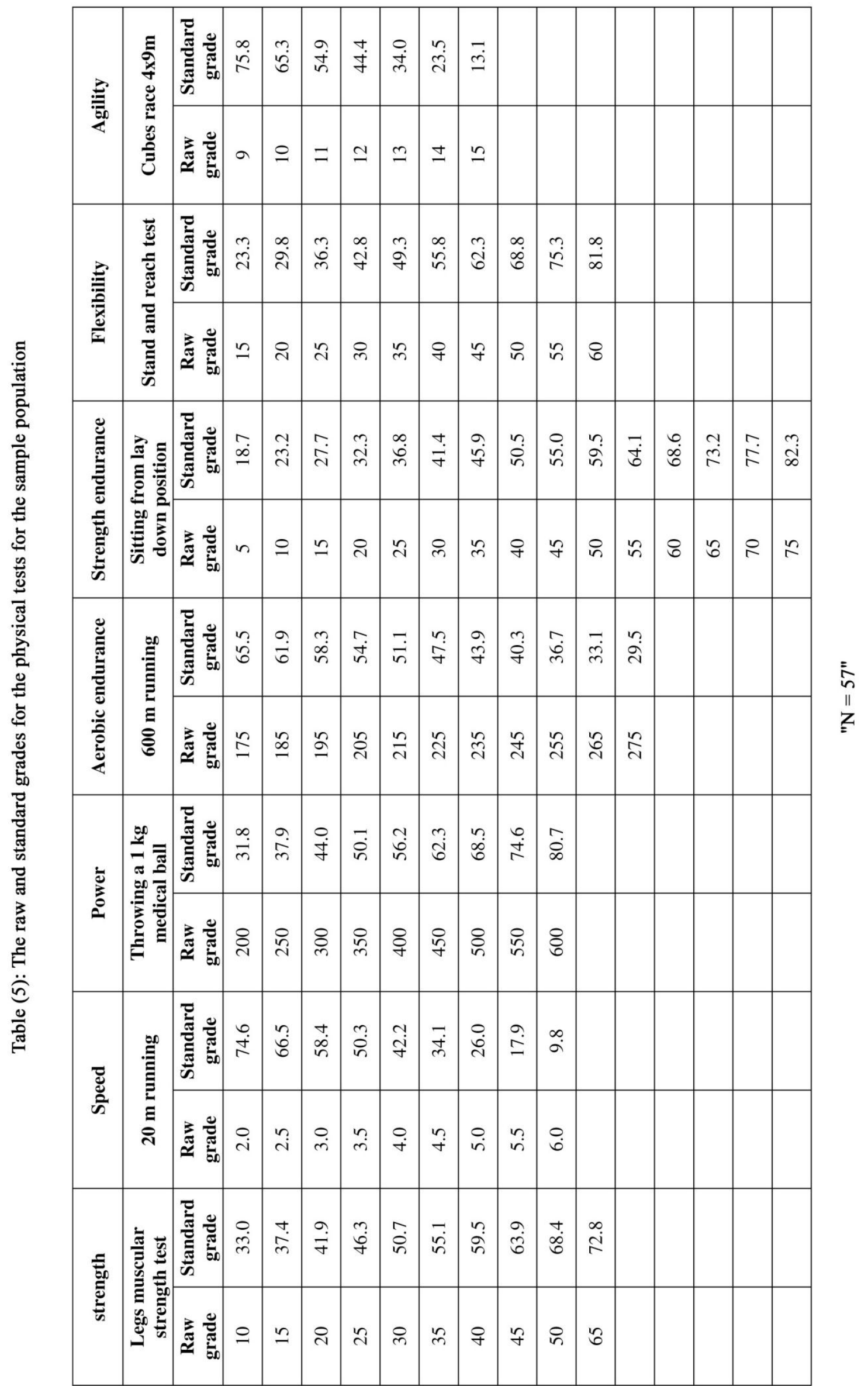




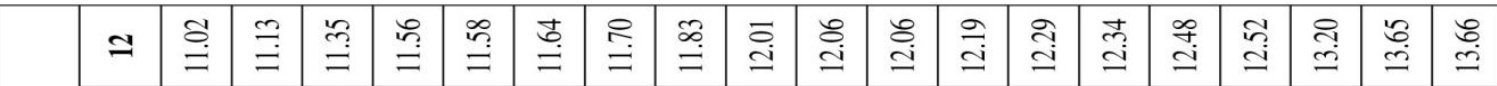

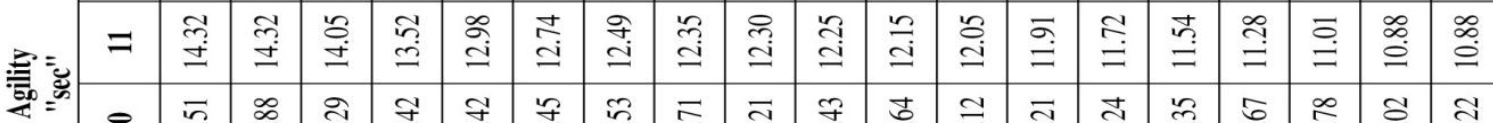

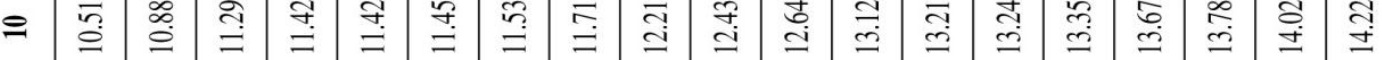

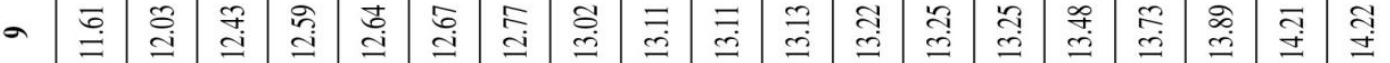

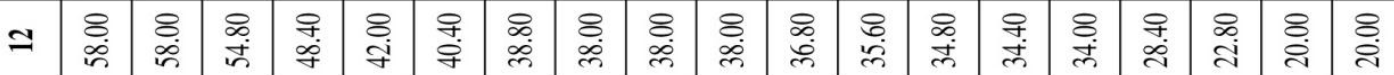

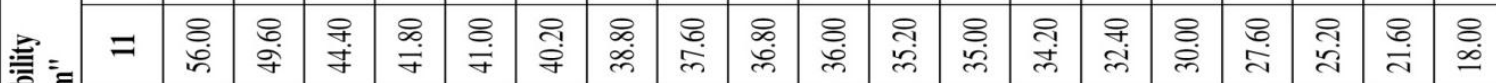

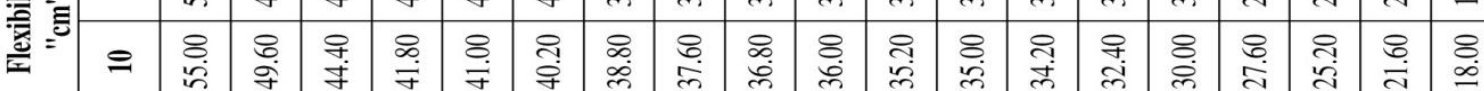

- 8 :

a भं

ح

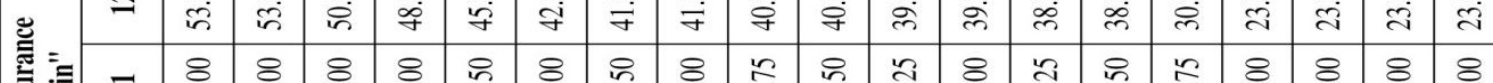

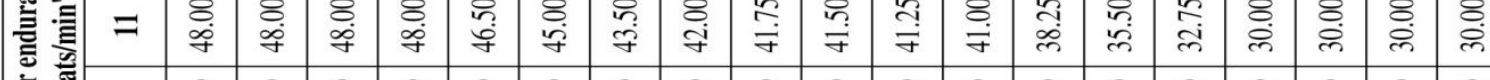
茞

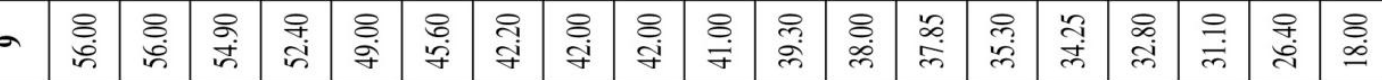

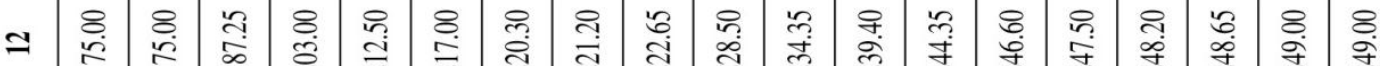

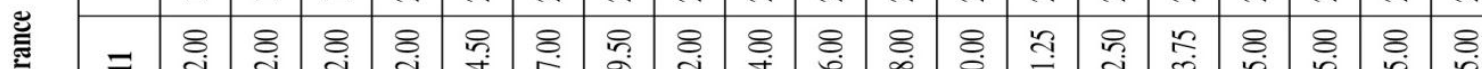
衰= = 产 =

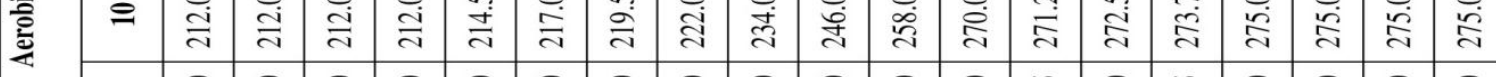

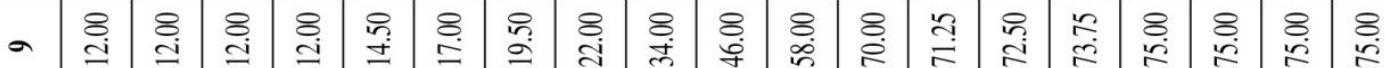
2 8 .

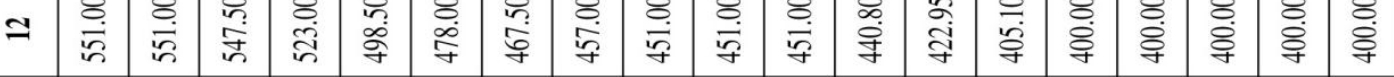

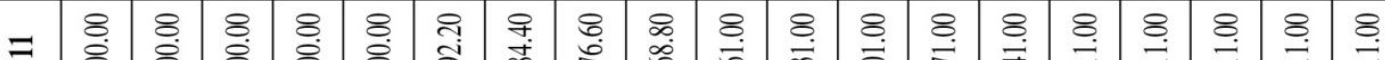

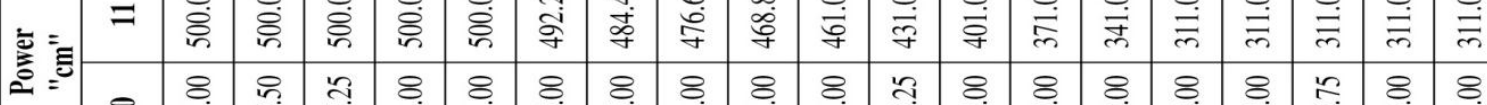

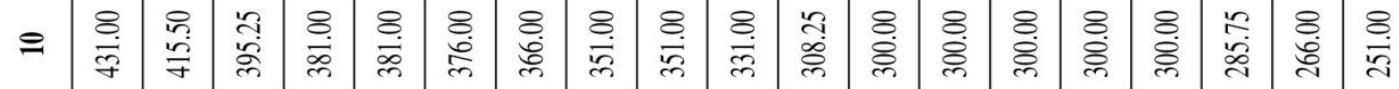

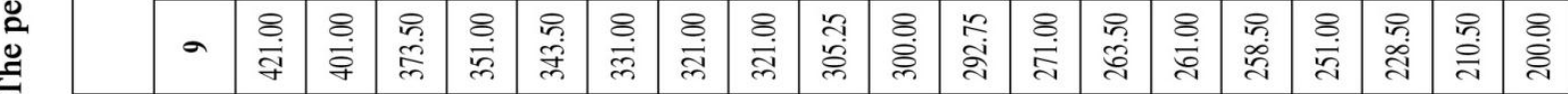

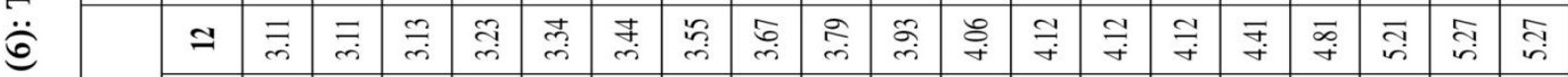
雚

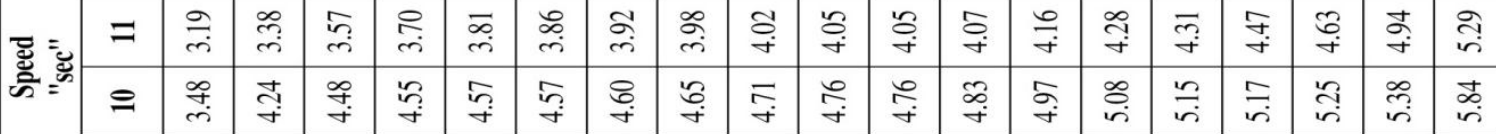

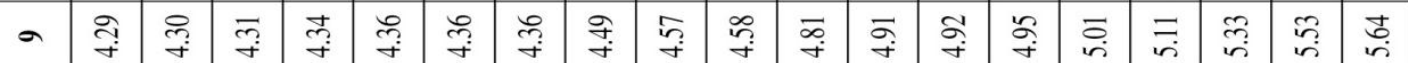

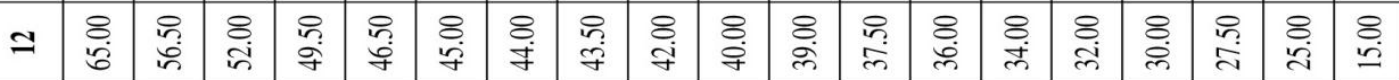

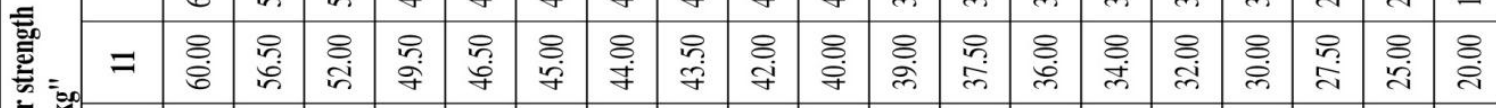
謇

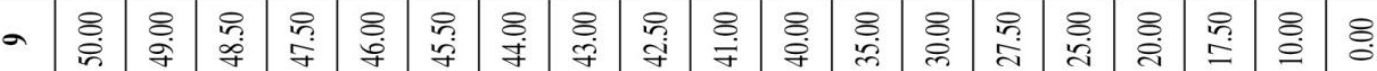

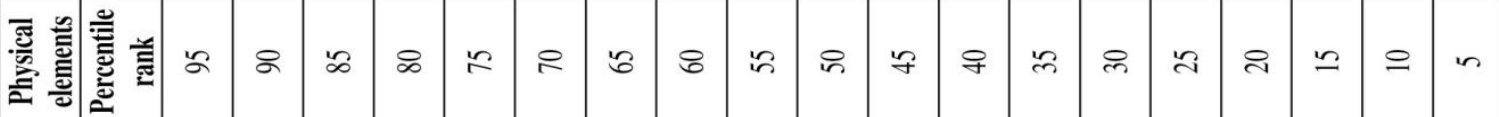




\section{Discussion:}

\section{Strnegth:}

Table 6 shows that strength has a linear relation with age and this is confirmed in Rateb et al's study (2005) that there is a linear relation between age and strength development as strength can be doubled in this age level and this development is faster for the lower limbs muscle group than the upper limbs.

Table (6) shows that it was possible to determine the standard grades that meets the raw grades for the tests of physical abilities which will be used in evaluating and selecting tennis talented female juniors.

Tables (5) and (6) shows that the raw and standard grades for muscular strength had a maximum of 65 which met the standard grade of 72.8 and the minimum raw grade 10 met the standard grade of 33 which means that the limits of standard grades lies between 33 and 72.8. in the same table also it is showed that the 5th percentile ranks for the 4 ages 9, 10, 11, 12 years were $0,10,20,15$ respectively and the 95th percentile ranks for the same ages were 50, $50,60,65$ respectively which means that the muscular strength grades increases as the age increases.

Further researches proved that there is a relation between strength and age as strength tends to increase during the first 20 years of life, then remains constant for around 5 to 10 years then it tends to decrease again until death.

Youssef dahab et al (2004) confirmed that strength can be affected with factors like the length of the muscle, age, sex, growth rate, training intensity and the muscle physiological sector as well.

Hussien (1998) and Eiben (2005) also mentioned that there is a gradual development in the levels of muscular strength that reaches its peak in the age of $11-12$ years. (12:74) (20)

\section{Speed:}

It is well-noted from previous studies and current results that speed also is connected to age with a linear function This agrees with what Rateb (1990) mentioned that there is a linear relationship between age and speed in the age between $7-17$ where it increases with a percentage of $50 \%$ for boys and $25 \%$ for girls.
Table (5) also shows that the raw grades for speed test had a limit between 2 and 6 with standard grades between 9.8 and 74.6 respectively where in table (7) the percentile ranks for the four age stages were 5.64, 5.84, $5.29,5.27$ for the ages of $9,10,11,12$ years respectively where the 95 th percentile rank met the grades of $4.29,3.48,3.19,3.11$ respectively which means that the speed increases as the age increases.

\section{Power:}

Table (5) shows that raw grades for power test had a limit between 200 and 600 that met with a limit of standard grades between 31.8 and 80.7 respectively. Also table (7) shows that the percentile ranks for power test for the four age stages were 200, 251, 311, 400 respectively, where the 95th percentile rank was met by the grades 421, 431, 500, 551 respectively which means that power increases as age does.

Rateb (1990) stated that power increases significantly in the age stage between 7 and 12 years for girls.

\section{Aerobic endurance:}

Table (5) also shows that the raw grades for aerobic endurance test had a limit between 275 and 175 with standard grades between 29.5 and 65.5 respectively where in table (7) the percentile ranks for the four age stages were $275,275,275,249$ for the ages of $9,10,11,12$ years respectively where the 95th percentile rank met the grades of 212, 212, 212, 175 respectively which means that the aerobic endurance increases as the age increases.

Allawi et al (2001) stated that strength affects endurance positively but in childhood the heart rate is higher and the amount of oxygen in blood as well as the amount of blood that is pumped through the heart muscle is smaller which leads to early fatigue that might affect the results of endurance tests negatively.

\section{Strength endurance:}

Table (5) also shows that the raw grades for strength endurance test had a limit between 5 and 75 with standard grades between 17.8 and 82.3 respectively where in table (7) the percentile ranks for the four age stages were 18, $25,30,23$ for the ages of $9,10,11,12$ years respectively where the 95 th percentile rank met the grades of $56,74,48,53$ respectively which 
means that the strength endurance might increase or decrease in relation to the age.

Rateb et al (2005) stated that the growth rate for the strength endurance element can be followed up through measuring the strength of arms and abdomen muscle groups. (20:92)

\section{Flexibility:}

Table (5) also shows that the raw grades for flexibility test had a limit between 15 and 60 with standard grades between 23.3 and 81.8 respectively where in table (7) the percentile ranks for the four age stages were 26, 18, 18, 20 for the ages of $9,10,11,12$ years respectively where the 95th percentile rank met the grades of $42,55,56,58$ respectively which means that the flexibility levels increases as the age increases.

Rateb et al (2005) stated that flexibility is very specific which means that a child with a flexible shoulder can have a less flexible hip.

\section{Agility:}

Table (5) also shows that the raw grades for agility test had a limit between 15 and 9 with standard grades between 13.1 and 75.8 respectively where in table (7) the percentile ranks for the four age stages were 14.22, 14.22, $10.88,13.66$ for the ages of $9,10,11,12$ years respectively where the 95th percentile rank met the grades of 11.61, 10.51, 14.32, 11.03 respectively which means that agility increases as the age increases.

This agrees with the findings of Rateb (1990) that girls achieves a lower percent of $8 \%$ in increased agility in this age stage than boys in the same age who can achieve a rate of $12 \%$ in increased agility. (19:334)

Thus the research thesis has been answered concerning building a standard level for some fitness elements as muscular strength, speed, aerobic endurance, muscular endurance, agility, power and flexibility for tennis female juniors from $9-11$ years old.

\section{Recommendations:}

The researcher recommends using these standard levels in evaluating the physical abilities for tennis female juniors from $9-12$ years old in the process of selection and talent identification.

\section{References:}

1. Aboelela Abdelfatah: physiological basics for sports training - 1st Ed. Dar Elfekr Elarabi Cairo, 1997.

2. Amin Elkholy \& Gamaleldin Elsahfie: Tennis (History - Technical skills - Tactics - Playing rules) - 1st Ed. Dar Elfekr Elarabi, 2001.

3. Amrallah Elbosaty: The Basics, fundamentals and applications of sports training - Monshaat Almaaref - Alexandria, 1998.

4. Dareen Gabr: Predicting tennis technical levels in scope of some physical and morphological variables, the faculty of sports education for women, Zagazig University, Egypt, 2004.

5. Darlene A. Kluka: Talent identification, Long term athlete development (Department of Biokinetics, Sport and Leisure Sciences, University of Pretoria - 2008) http://web.up.ac.za/sitefiles/File/1795/hpc2/Tale nt\%20 Identification.pdf.

6. Doug MacCurdy: Talent Identification Around The World And Recommendations For The Chinese Tennis Association (ITF coaching

http://jinjitennis.com/junior_lessons/tips/Talent_ Identification.pdf , 2011).

7. Elaine Wolstencroft: Talent Identification and Development: An Academic Review (A report for sports Scotland by The University of Edinburgh $\quad-\quad$ 2002) http://researchrepository.napier.ac.uk/2493/1/Ac ademic_Review.pdf.

8. Ellin Wadiea Farag: Tennis (learning coaching - evaluating - refereeing) - 2nd Ed. Monshaat Elmaaref, Alexandria, 2007.

9. Essam Abdelkhalek: Sport Training - Theory and application, 12th Ed. Monshaat Elmaaref, Alexandria, 2005.

10. Gallahue, L.D.: Development physical Education Of Today Elementary Children, 1 St., ed., Macmillan pu blushing, 1993.

11. Hassan Aboabda: New trends in football coaching and planning - Elesheaa library and press house, 1st Ed. Alexandria, 2001. 
12. Kasem Hassan Hussien: The science of sports training for several ages, Dar Elfekr, Oman, Jordan, 1st Ed. 1998.

13. Kirchner,G: Physical education for Elementary school Children, 7 th., and ed., w M. C. Brown Co., U.S.A, 1988.

14. Lacourse, M. \& Young, D.: Talent Identification in Junior Tennis players, CaliforniaStateUniversity at Long Beach, 1995.

15. Laila Farahat: Measurement and evaluation in sports education, Publishing book center, Cairo, 2001.

16. Mofty Ibrahim Hamad: Sports training for males and females in childhood and teenaging, 1st Ed. Dar Elfekr Elarabi, Cairo, 1996.

17. Mohamed Allawi \& Mohamed Nasreldin: Movement performance tests, 5th Ed. Dar Elfekr Elarabi, Cairo, 2001.

18. Mohamed Hassan Allawi: Growth Psychology, 1st Ed. Publishing book center, Cairo, 1998.

19. Osama Kamel Rateb: Movement growth for children and teenagers - Dar Elfekt Elarabi Cairo, 1990.

20. O. G. Eiben, A. Barabás and Á. Németh: Comparison of Growth, Maturation, and
Physical Fitness of Hungarian Urban and Rural Boys and Girls, J. Hum. Ecol., 17(2): 93-100 (2005).

21. Osama Rateb \& Ibrahim Khalifa: Growth and motivation in directing the movement activities for children in school physical activities, Dar Elfekr Elarabi, Cairo - 2005.

22. R. Burgess: Talent identification $-\mathrm{A}$ review (http://talentidisn.blogspot.co $\mathrm{m} / 2009 / 10 /$ review-talent-identification-byr.html - 2009).

23. Sam Ellyn: Talent Identification in Tennis (http://www.livestrong.com/article/483884talent-identification-in-tennis, 2011).

24. Sayed Mohammad Ali Mirhosseini \& Samira Golriz \& Farideh Hadavi: Talent identification in soccer players aged 10-12 years, Journal of Sports Science and Medicine, http://www.jssm.org (2007).

25. Wall, j., \&Murray,N: Children \& Movement, physical education in the Elementary school, 2 nd, Brown \& Benchmark, U.S.A, 1995.

26. Youssef Dahab et al.: Introduction in sports biology, Elhorrya library, Cairo, 2004. 